\title{
PRÁTICA PEDAGÓGICA EM EDUCAÇÃO FÍSICA PARA A EDUCAÇÃO INTEGRAL EM TEMPO INTEGRAL
}

\author{
Solange Izabel Balbino \\ Universidade Federal de Mato Grosso do Sul, Campo Grande, Mato Grosso do Sul, Brasil \\ Sônia da Cunha Urt \\ Universidade Federal de Mato Grosso do Sul, Campo Grande, Mato Grosso do Sul, Brasil
}

\begin{abstract}
Resumo
Este estudo busca entender o olhar do professor de Educação Física para sua prática pedagógica e o desenvolvimento do trabalho docente em uma escola de tempo integral. O objetivo é compreender o lugar da Educação Física nas escolas de educação integral em tempo integral. A coleta de dados foi realizada por meio da entrevista-narrativa e, em seguida, passamos a uma análise microgenética sob a perspectiva da Teoria Histórico-cultural. Quanto ao tema, compreendemos que a prática do professor está comprometida com a formação integral do aluno e com a qualidade do tempo ampliado na escola. Contudo, entendemos que ainda falta aos sistemas de gestão escolar uma concepção ubíqua da educação integral e da ampliação da jornada diária dos alunos.
\end{abstract}

Palavras-chave: Educação Física e Treinamento. Professor. Prática Pedagógica.

\section{PEDAGOGICAL PRACTICE IN PHYSICAL EDUCATION FOR INTEGRAL EDU- CATION IN FULL TIME}

\begin{abstract}
This study seeks to understand the perspective of a physical education teacher's about his pedagogical practice and the development of teaching work in a full-time school. The objective is to understand the place of Physical Education in full-time schools of integral education. Data collection was performed through interview-narrative and then we proceed to a microgenetic analysis from the perspective of Historical-Cultural Theory. Regarding the subject, we understand that the teacher's practice is committed to the integral formation of the students and to the quality of the extended time in the school. However, we believe that, still, the school management systems lacks a ubiquitous conception of integral education and the expansion of the students' daily journey.
\end{abstract}

Keywords: Physical Education and Training. Teacher. Pedagogical Practice.

\section{PRÁCTICA PEDAGÓGICA EN EDUCACIÓN FÍSICA PARA LA EDUCACIÓN IN- TEGRAL EN TIEMPO COMPLETO}

\section{Resumen}

Este estudio busca entender la mirada del profesor de Educación Física para su práctica pedagógica y el desarrollo del trabajo docente en una escuela de tiempo completo. El objetivo es comprender el lugar de la Educación Física en las escuelas de educación integral en tiempo completo. La recolección de datos fue realizada por medio de entrevista narrativa y luego pasamos a un análisis microgenético bajo la perspectiva de la Teoría Histórico-cultural. Sobre el 
tema, comprendemos que la práctica del profesor está comprometida con la formación integral del alumno y con la calidad del tiempo ampliado en la escuela. Sin embargo, entendemos que, aún falta a los sistemas de gestión escolar una concepción ubicua de la educación integral y de la ampliación de la jornada diaria de los alumnos.

Palabras clave: Educación Física y Entrenamiento. Profesor. Práctica Pedagógica.

\section{Introdução}

Esse texto é um exercício de observar a concepção que o professor tem de sua prática pedagógica e de quais meios se utiliza para defini-la no cotidiano escolar. Especificamente, observamos o professor de Educação Física em uma escola municipal de tempo integral.

Optamos por ouvir a história do professor, por meio da entrevista narrativa, pois nosso interesse é compreender o olhar do professor para sua prática docente. Não queríamos perguntar aos professores quais as estratégias pedagógicas utilizadas por eles, ao contrário, pretendíamos subtrair essas informações de suas falas. Especialmente, procuramos, por meio da análise da história contada, entender o dia a dia desse profissional e suas concepções acerca de sua atividade docente neste modelo educacional amplamente debatido nos últimos anos.

Para compreendermos a prática profissional, o cotidiano escolar das escolas de tempo integral e também a Educação Física Escolar, apoiamo-nos em autores que, ao longo de seus trabalhos, têm contribuído no âmbito dessas discussões.

É necessário considerar, entretanto, o contexto em que se desenvolve o trabalho do professor participante, a maneira como tem se estabelecido e determinado o seu ambiente de trabalho e, de modo geral, o que atribui sentido à sua prática pedagógica.

A experiência relatada nos faz refletir em questões que estão além dos conteúdos ensinados e da maneira como essas aulas se desenvolvem. Isso nos faz pensar o motivo, tanto de as aulas serem como são, quanto de o professor ter esse olhar de si e seu trabalho.

\section{Procedimentos Metodológicos}

A perspectiva metodológica desse estudo foi o Materialismo Histórico Dialético, alicerçada na Teoria Histórico-Cultural. De acordo com Frigotto (1987), o método vincula-se à concepção de realidade, de mundo e de vida em conjunto. Nesse sentido, constitui-se no processo de apreender, revelar e expor a estruturação, o desenvolvimento e a transformação dos fenômenos sociais. Segundo Martins (2015), o Materialismo Histórico Dialético é uma possibilidade teórica para interpretar a realidade, entendendo que a dialética oferece um caminho para a interpretação dos dados em sua essencialidade.

Utilizamos a entrevista narrativa realizada com um professor de Educação Física de uma escola municipal de tempo integral de Campo Grande/MS, pois entendemos se tratar de uma ferramenta de coleta que permite a interpretação subjetiva dos registros, dinamizando a qualidade da observação dos fatos. Os dados são parte de uma pesquisa maior acerca das ações desenvolvidas na área da Educação Física nessas escolas. Essa entrevista, especificamente, foi um momento preliminar dentro da pesquisa, em que procuramos traçar um panorama geral do funcionamento das escolas de tempo integral e da função da Educação Física em seu projeto político pedagógico para, em seguida, nos aprofundarmos nas ações desenvolvidas nesse contexto.

Optamos pela narrativa, pois acreditamos que narrar é ação de representação pela qual o ser humano evidencia sua vivência e experimentação do mundo. É a reconstrução da história individual e coletiva, em que o indivíduo expressa sua visão de determinado acontecimento histórico. 
As narrativas como recurso metodológico para a pesquisa em educação são instrumentos favoráveis para a compreensão da memória e da história dos sujeitos envolvidos na investigação proposta [...], por meio das narrativas, o narrador externa suas concepções de mundo, expõe suas ideias, projetos e ideologias, assim como suas limitações, evidenciando sua identidade. (SIMÃ̃; URT, 2013, p. 112).

As autoras acreditam na eficiência do recurso metodológico das narrativas, para possibilitar a compreensão da constituição do sujeito de forma ampla e contextualizada, o que atende a nossas expectativas e objetivos.

Clandinin e Connely (2011) afirmam que a narrativa é um meio para compreender a experiência vivida pelo outro, uma colaboração entre o pesquisador e o indivíduo participante da pesquisa. Dessa interação surge a compreensão do que é dito e do que fica 'por dizer', e cabe ao pesquisador subentender diante dos contextos expostos.

Para a análise, interpretamos o discurso evitando a superficialidade das interpretações. Entendemos que a profundidade de tais interpretações se dá na interação entre os sujeitos da pesquisa, pesquisador e pesquisado, e na construção dessa narrativa que foi gravada, transcrita e analisada.

Entendemos que ao realizar a pesquisa narrativa, o pesquisador tem a oportunidade de fazer suas análises de forma mais completa. Para tanto, precisa estar atento às diversas formas de expressão do sujeito envolvido na pesquisa. Parece-nos fundamental haver uma séria análise metodológica, um bom relacionamento entre o pesquisador e os sujeitos da pesquisa [...]. (SIMÃO; URT, 2013, p. 117).

Assim justificamos nossa opção por tal procedimento de coleta de dados e acreditamos na clareza e verdade produzida em sua análise. Desse modo colaboramos para o entendimento da prática docente dentro de um contexto social e histórico e, de fato, a partir do olhar do professor.

É importante esclarecer que o participante, cuja narrativa analisamos aqui, é um professor de Educação Física com onze anos de formação inicial e trabalha há dez anos com Educação Física escolar, sendo nove na mesma escola de tempo integral.

\section{Reflexões acerca da atividade docente}

Para analisar a atividade docente na narrativa do entrevistado, precisamos primeiro definir o que compreendemos por prática docente e o que é, em nossa perspectiva, o trabalho do professor. Para tanto buscamos essa compreensão na Teoria Histórico-cultural, base teórica que sustenta a nossa pesquisa. Desse modo, procuramos entender, junto a estudiosos dessa teoria quem é o professor, o significado de seu trabalho para a sociedade e o sentido atribuído a esse trabalho por ele próprio.

Vigotski (2003) afirma a necessidade de se compreender a natureza psicológica do trabalho do professor, sem a qual, o autor adverte, não é possível abranger integralmente, num estudo, os processos educativos. $\mathrm{O}$ autor nos mostra que o professor é mais do que uma fonte de conhecimento e repetidor de ideias, seu papel é o de transformar e organizar o ambiente social, que é o próprio fator educativo.

Desse modo os estudiosos da atividade docente, nesta perspectiva, enxergam o professor como indivíduo participante do processo de ensino e aprendizagem. O sujeito que organiza as bases pedagógicas para a aquisição e a apropriação do conhecimento.

Facci (2004) esclarece quanto à função da educação escolar e, por conseguinte, do professor, cujo interesse primordial é levar o aluno à apropriação do conhecimento de modo que se possam humanizar, o que determina que a atividade docente deva estar contextualizada 
social e historicamente com o indivíduo e seu meio. A autora afirma que por meio do processo educativo intencional e sistematizado, o aluno supera os conhecimentos cotidianos, incorporando o conhecimento científico. A isso ela denomina desenvolvimento cultural, o qual contribui para o desenvolvimento geral do indivíduo.

A apropriação desses conhecimentos científicos levará o aluno a conhecer de forma mais concreta, por meio da mediação das abstrações, a realidade da qual ele faz parte. Assim, o adulto mais desenvolvido, no caso o professor, deve ter como meta transmitir para os alunos esse conhecimento científico de forma sistematizada. (FACCI, 2004, p. 228).

Nesse sentido, Duarte (2013) considera que a educação e a prática pedagógica atuam na consciência do indivíduo acerca de seu contexto social e da totalidade humana. Ou seja, o processo educativo direciona o processo de humanização do sujeito, ainda que, de acordo com o autor, deliberadamente em concordância com as próprias concepções.

[...] a existência de teorias pedagógicas que defendam a existência de práticas pedagógicas não diretivas não altera o fato de que a ação do professor sempre carrega um posicionamento sobre o conhecimento, sobre a realidade humana e sobre o processo formativo das novas gerações [...]. (DUARTE, 2013, p. 124).

Assim, compreendemos que, na educação escolar, a atividade docente influencia a formação psicológica do aluno, desempenhando a função mediadora entre o singular e o plural, o abstrato e o concreto.

Consideramos imprescindível buscar o sentido atribuído pelo sujeito à sua atividade pedagógica para identificar o que Urt (2012) define como 'sentido pessoal e significado social' do trabalho docente. "Pensando no sentido subjetivo do trabalho docente, é preciso estar atento ao que motiva e ao que incita o trabalho do professor, ou seja, qual é o sentido pessoal da atividade para o professor" (URT, 2012, p. 32).

\section{Considerações acerca da educação em tempo integral}

Para entender o espaço da Educação Física num determinado projeto de educação, precisamos entender esse projeto. Portanto, faz-se necessário responder o que, de fato, é a educação integral em tempo integral no cenário atual e compreender as suas relações com a sociedade e seus objetivos para o aluno.

Cavaliere (2014) afirma que a escola pública de tempo integral atual é uma resposta à necessidade de melhoria do ensino público e ao aumento da qualidade educacional. E surge em função dessa expectativa, em direção ao atendimento dessas necessidades.

Contudo, o aumento da jornada escolar suscita inúmeras dúvidas e discussões quanto à viabilidade de atender o objetivo de elevar o padrão de qualidade da escola pública. Um exemplo da origem dessas discussões é a existência de modelos diferentes para a realização da ampliação da jornada.

Os modelos de organização para realizar a ampliação do tempo de escola que vem se configurando no País podem ser sintetizados em duas vertentes: uma que tende a investir em mudanças no interior das unidades escolares, de forma que possam oferecer condições compatíveis com a presença de alunos e professores em turno integral, e outra que tende a articular instituições e projetos da sociedade que ofereçam atividades aos alunos no turno alternativo às aulas, não necessariamente no espaço escolar, mas, preferencialmente, fora dele. (CAVALIERE, 2009, p. 52). 
Percebe-se que um desses modelos possibilita o fortalecimento da educação pública, oferecendo uma educação integral, compreendendo o sujeito em sua totalidade. Já o outro não fortalece essa ideia, reforçando o conceito de integralidade da ocupação do tempo do aluno e não de sua educação integral.

A troca com outras instituições sociais e a incorporação de outros agentes educacionais são fundamentais para o enriquecimento da vida escolar, mas as formas alternativas de ampliação do tempo educativo que não tem como centro a instituição expõem-se aos perigos da fragmentação e da perda da direção. (CAVALIERE, 2009, p. 61).

Compreendemos a escola de tempo integral como uma proposta para melhorar o acesso à educação de qualidade, porém há que se manter um olhar atento à maneira como se desenvolve na prática.

Nesse sentido a questão central no que tange às escolas de educação integral em tempo integral é, justamente, se a articulação de saberes que estão além da escola, será entendida como educativa e trazida para o cotidiano escolar. Assim, aumentar o tempo de permanência na escola requer ampliar as possibilidades educativas do aluno e não o manter por mais tempo sob a guarda da escola.

\section{Pensando a Educação Física escolar}

Embora a Educação Física seja a ciência que estuda e trabalha a cultura corporal e o movimento humano e, no espaço escolar, os conteúdos a ela relacionados sejam os elementos da cultura corporal, os esportes, as danças, as lutas, a ginástica e a capoeira, entre outros, acreditamos que nestes conteúdos a disciplina contribua para a formação de um sujeito integral e assim, deve estar articulada ao projeto político pedagógico da escola.

Para realizar tal tarefa é fundamental entender o objeto da EF, o movimentar-se humano, não mais como algo biológico, mecânico ou mesmo apenas na sua dimensão psicológica, e sim como fenômeno histórico-cultural. (BRACHT, 1999, p. 81).

O autor afirma que a Educação Física só alcançará esse entendimento quando tomarmos as ciências humanas e sociais como referência além das ciências da saúde. Só assim seus conteúdos alcançarão uma mudança no imaginário social.

Deste modo, para compreender as relações da Educação Física e da educação escolar é preciso considerar que sua presença, tal como é, na escola atual é recente e a disciplina vem conquistando seu espaço no currículo escolar. Contudo, ainda encontramos nas comunidades escolares, indivíduos que a entendem, apenas como tempo livre ou, ainda, responsável por disciplinar e desenvolver o corpo no sentido estritamente motor.

Compreendemos que a Educação Física está na educação escolar e deve, ao ocupar esse espaço, possibilitar o acesso dos alunos, por meio de seus conteúdos, a elementos educativos diversos. É importante tornar as atividades ligadas a ela um elemento a mais no processo educativo, utilizando-se de todos os seus aspectos para possibilitar o desenvolvimento integral do aluno.

Os estudiosos da Educação Física escolar entendem que ela deve contemplar o fenômeno educativo e o indivíduo em sua totalidade. Estabelecendo relações entre os ambientes, os sujeitos e os fatos.

Medina (2008) afirma que podemos entender a Educação Física como a educação do movimento e pelo movimento que, por meio de atividades específicas possibilita o desenvolvimento integral dos indivíduos. Essa maneira de entender e fazer Educação Física na escola 
pode renovar e transformar os sentidos que se tem da sociedade e suas determinações e, consequentemente, desenvolver o autoconhecimento e a autonomia nos alunos.

Assim, consideramos que a Educação Física deve assumir sua responsabilidade e de posse de seus conteúdos básicos desenvolver o ser humano, em conjunto com toda a escola. $\mathrm{E}$ não há, em nossa concepção, melhor maneira de se desvendar seu desenvolvimento na escola do que pelo olhar do professor que a ensina.

\section{Discussão dos resultados}

De acordo com Piatti e Urt (2014), a pesquisa oferece ao pesquisador e à sociedade a oportunidade de reconhecer sujeitos e situações que, trabalhadas com o devido rigor, podem fornecer o reconhecimento e a abrangência de temas reais, favorecendo a melhoria das situações discutidas.

Nesse caso, realizar a pesquisa com o professor permite experimentar o cotidiano do trabalho escolar por meio de sua fala, e construir conhecimentos que, acreditamos, são relevantes para a discussão do tema abordado. No primeiro momento, entendemos que não é possível compreender esse lugar sem ter a compreensão da totalidade do modelo escolar estudado e, na fala do professor, entendemos que esse sistema é complexo e o que ocorre em determinado momento ou espaço do ambiente escolar está ligado a outro.

Então é um ambiente dinâmico, não é?! Vamos dizer assim, é uma rotina que muitas vezes não é rotina, porque tem vários professores diferentes dando aula a cada dia. Então é (sic) essas transformações que acontecem tanto da criança como até no ambiente e isso influencia muito na questão das atividades. (Professor R., 2017)

Vigotski (1991) afirma que os temas abordados na escola devem ter relação específica com o desenvolvimento do ser humano e ser ampliados nessa direção, como uma espiral que vai se expandido. Assim, os processos educativos escolares precisam estabelecer uma conexão lógica entre os conhecimentos historicamente produzidos pela humanidade e o contexto social do aluno. Nesse caso, a Educação Física oferece um vasto campo de conhecimento acerca de elementos produzidos historicamente pelo homem, possíveis de serem desenvolvidos na escola, inclusive em articulação com os demais componentes curriculares, possibilitando uma educação integral que ocorre em tempo integral.

Posto isso, percebemos que, para o professor, situar em que contexto surge este modelo atual de escolas em tempo integral é muito importante para definir sua prática pedagógica e, mesmo, para defendê-la e justificá-la. Nesse sentido, o professor expõe que a implantação dessas escolas, assim como afirma Cavaliere (2014), é uma necessidade social que vem satisfazer o apelo da sociedade por melhores e mais amplas condições e possibilidades educacionais.

[...] ela vem pra poder suprir, né?!, dentro de uma realidade, as transformações que a sociedade está vivendo. Então, assim, ela vem como uma forma de poder dar uma educação integral devido às novas configurações de família, às novas configurações sociais, à questão do tempo. (Professor R., 2017).

Tanto neste, quanto noutros momentos da narrativa, compreendemos que o professor entrevistado identifica como objetivo principal da escola de tempo integral a formação integral do aluno por meio de atividades diversificadas. Contudo, é responsabilidade do pesquisador enxergar além do que está aparente, além do que fica evidente. Como afirma Vigotski (2007), para compreender um fato como realmente é, precisamos olhar além do que ele aparenta ser. Assim, por meio da análise do que diz o professor é que procuramos entender a essência, o que está nas entrelinhas. 
Desse modo, quando o entrevistado nos fala de configurações sociais e familiares, isso nos remete às concepções evidenciadas pelo senso comum. Apesar de o ideário da escola ser fascinante e revolucionário, o que ocorre na prática muito se assemelha à assistência social cujo intuito é manter as crianças sob a guarda do Estado enquanto os responsáveis estão ausentes, seja devido ao aumento das jornadas de trabalho ou à própria inserção e permanência da mulher no mercado de trabalho.

Sobre essa discussão entre educação e assistencialismo, Cavaliere (2014) afirma,

[...] não parece haver dúvida de que uma das grandes motivações para a ampliação da jornada escolar é a necessidade das famílias de terem as crianças e adolescentes protegidos e assistidos durante o período de trabalho dos pais. (CAVALIERE, 2014, p. 1211).

Desse modo, discutindo a Educação Física escolar no âmbito de uma pedagogia concreta, que perceba o ser humano, é necessário compreender, de acordo com Saviani (2015), que o sujeito deve ser entendido como uma síntese de suas relações sociais, sem isso não se poderá chegar a uma via de superação da educação escolar tradicional.

[...] enquanto a pedagogia tradicional considera os educandos como indivíduos abstratos, isto é, como expressões particulares da essência universal que caracteriza a realidade humana, a pedagogia moderna considera os educandos como indivíduos empíricos, isto é, como sujeitos singulares que se distinguem uns dos outros pela sua originalidade, criatividade e autonomia, constituindo-se no centro do processo educativo. (SAVIANI, 2015, p. 79).

Assim, diferente de ambas, que excluem ou naturalizam as relações sociais, uma pedagogia concreta enxerga o aluno como indivíduo concreto, que é singular, mas também plural, que existe de acordo com o meio em que vive e que é uma síntese dessas relações.

Com isso queremos esclarecer que o aluno está posto numa sociedade que não escolheu, como afirma Saviani (2015), e desse modo não faz tudo de acordo com a própria escolha. Nesse sentido, o indivíduo encaminha a educação escolar para romper com essas pseudo convicções; logo, é necessário fazer uma Educação Física escolar concreta, que leve o aluno a refletir os elementos da cultura corporal e superar a reprodução dos padrões já estabelecidos.

Não afirmamos isso no intuito de fomentar a ideia de que esse é o objetivo real das escolas de tempo integral e sim para demonstrar que, mesmo na fala de um profissional comprometido com a educação integral dos seus alunos, ainda encontramos tais considerações. Consideramos que, quando narra seu cotidiano escolar, o professor demonstra seu entusiasmo com o projeto de educação integral em tempo integral e trabalha para que sua prática promova novas possibilidades à formação de seus alunos, oferecendo atividades diferenciadas que incentivem a criticidade do aluno.

Nesse caso, podemos dizer que o professor caminha para uma atividade docente articulada ao que Vigotski (2003) define como o ideal do trabalho do professor, conforme já apontamos neste texto. O professor instiga o desejo de saber, de conhecer e de desenvolver-se do aluno e, por fim, organiza o espaço tornando-o adequado ao seu desenvolvimento.

Em sua fala, o professor sempre coloca a Educação Física em consonância com esses objetivos de formação e desenvolvimento integral. O professor define que o trabalho da Educação Física escolar em virtude do aumento da jornada diária foi potencializado, pois no tempo regular cada turma de alunos tem apenas dois ou três encontros com o professor de Educação Física.

Nesse sentido, de que a ampliação da jornada faz com que se diversifique a prática, em comparação com as demais escolas, o professor afirma que "[...] aqui tem algumas atividades específicas que essa criança pode vivenciar, coisa que em outra escola de meio período ela só 
tem os conteúdos da grade curricular, da disciplina de Educação Física" (Professor R., 2017). $\mathrm{O}$ professor se refere às Atividades Curriculares Complementares (ACCs), que são as atividades desenvolvidas na jornada ampliada. E no que diz respeito à dinâmica escolar, de acordo com o professor, não se pode considerar as atividades como sendo de contra turno, pois o expediente de aula é único e tanto as atividades complementares quanto as do núcleo integrador do currículo ocorrem simultaneamente com alunos e em espaços diferentes.

Esse é um ponto interessante que vai ao encontro do que muitos entusiastas da educação integral almejam. Não se segregam as atividades, os componentes curriculares articulamse no mesmo propósito, diversificando as possibilidades educativas do currículo.

A afirmação de Cavaliere (2007) a esse respeito, por exemplo, demonstra essa concepção de escola em tempo integral,

O tempo integral seria um meio a proporcionar uma educação mais efetiva do ponto de vista cultural, com o aprofundamento dos conhecimentos, do espírito crítico e das vivências democráticas. A permanência por mais tempo na escola garantiria melhor desempenho em relação aos saberes escolares, os quais seriam ferramentas para a emancipação. (CAVALIERE, 2007, p. 1029).

Posto isso, voltamos à questão do lugar da Educação Física neste projeto educacional, e nesse ponto entendemos que, na concepção do professor, o que diferencia essa Educação Física da praticada na escola de jornada regular é mesmo a possibilidade de maior interação entre professor e aluno.

Enquanto em uma escola regular o aluno só poderá vivenciar o básico dos elementos da cultura corporal, na escola de jornada ampliada, além dessa vivência, eles terão acesso às novas possibilidades de trabalho com o corpo, contribuindo para a formação de sua consciência corporal e tomando consciência da coexistência dos demais corpos e do mundo a sua volta.

Nesse contexto, percebemos que as ACCs configuram as atividades que oferecem aos alunos oportunidades de formação integral, atividades em consonância com a atividade de estudo que não faria parte do currículo devido à escassez do tempo na jornada regular. São conteúdos relacionados à filosofia, à cultura e ao lazer, entre outros, que elevam a formação humana a outro patamar.

Nesse sentido, evidencia-se o que expõem Moll e Leclerc (2013) sobre a importância de integrar outros tempos, espaços e saberes ao currículo escolar, para explorar as experiências dos alunos de maneira mais abrangente e ampla, incluindo na vida cotidiana escolar atividades, saberes e espaços sociais como parte das ações curriculares.

Diante dessa discussão, ressaltamos a afirmação do professor quanto à educação em tempo integral, propondo a educação integral dos indivíduos, coadunando com os ideais da Educação Física, que entende o ser humano como um todo. E, entendendo o ser humano como um todo, encaminha as atividades desenvolvidas na direção de articular o ambiente complexo da escola e os trabalhos nela desenvolvidos.

Nesse sentido, Silva (2015) considera que um dos meios de integrar a Educação Física à escola é utilizando-a como um componente curricular obrigatório, ressaltando em seus conteúdos uma formação política do aluno, preparando-o para o exercício da cidadania. $\mathrm{O}$ autor afirma que para que tal fato ocorra é realmente necessário ampliar o leque de movimentos, assim como as estratégias pedagógicas.

Por último, ainda que o professor durante a narrativa reafirme o funcionamento da escola integral no campo pedagógico e não somente no aumento do tempo, ao ser questionado acerca da articulação entre núcleo integrador e ACCs, o professor esclarece que não existe essa articulação ou que a mesma não é uma prioridade. 
[...] então a gente (no integrador) tá (sic) trabalhando jogos. Pode ser no ACC, por exemplo, o de futsal, por exemplo, ele trabalha o jogo tá (sic), mas dentro da perspectiva do futsal. Então eles vão estar relacionados, mas não atrelados tá (sic), todos são independentes [...] isso pode acontecer, mas pode não acontecer também. (Professor R., 2017).

Em nosso entendimento essa prática perde a característica de tornar o projeto da escola um projeto de educação integral, pois nos sugere que dentro da mesma área do conhecimento, as propostas são independentes, não articulando um momento ao outro.

Soares et al. (1992) afirma que o componente curricular só tem sentido pedagógico se seu objeto de estudo se articula entre si e aos demais componentes. Nesse sentido, o objeto de tal disciplina deve ser indispensável à reflexão pedagógica do aluno e sua formação, a tal ponto que sua ausência comprometa a totalidade dessa reflexão.

Desse modo, entendemos que o professor, assim como a equipe escolar, segue os ideais de ampliar e melhorar a educação e, em sua prática, o professor está comprometido com a formação integral de seus alunos. Contudo, ainda se apresenta a falsa concepção de que ocupar o tempo do aluno com atividades diversificadas, mesmo que desarticuladas do conteúdo pedagógico, amplia e fortalece o processo educativo.

Percebemos em diversos sentidos as intenções do professor e o quanto se empenha para tornar sua prática pedagógica significante e relevante à formação do aluno, pois acredita na validade do plano escolar em que está inserido. Entretanto compreendemos que o comprometimento do professor com seus alunos e sua formação, assim como o projeto proposto pela escola são um caminho para a implementação e o fortalecimento da educação integral em tempo integral. Mas é necessário desfazer-se dos conceitos cristalizados que existem acerca do fazer pedagógico de um modo geral.

\section{Algumas considerações}

De acordo com a Teoria Histórico-cultural e a maneira com que ela nos permite interpretar os dados de determinado fato, consideramos que o professor participante vê sua área do conhecimento como fundamental à formação integral dos alunos. E mesmo que, em alguns momentos, possamos identificar as dificuldades encontradas para a implantação de uma verdadeira escola de educação em tempo integral, e ainda que o próprio professor não entenda esses pontos como dificuldades, encontramos um projeto educativo comprometido com a melhoria da educação pública e professores preocupados em fazer de sua prática docente um referencial na formação de seus alunos.

Posto isso, a Educação Física deve contemplar as diferentes dimensões dos alunos, e trabalhar o movimento humano para o desenvolvimento omnilateral do sujeito. Assim, trabalhando os elementos da cultura corporal no ambiente escolar, tanto no ambiente de aprendizagem integrador quanto nas ACCs, é possível compreender toda a expressão corporal contida nesses elementos.

Fica, nesse caso, o questionamento acerca da realidade dessas atividades no contexto escolar e como elas se materializam no cotidiano das ETIs. Faz-se necessário conhecer a realidade dessa complementariedade de atividades educativas e o quanto são sociais, políticas e transformadoras, a ponto de estarem inseridas na educação desses alunos, pois existir no Projeto Político Pedagógico de maneira contundente e se materializar de maneira vazia é empreender tempo e trabalho dos professores e dos alunos em vão.

Pensar uma escola de tempo integral que promova a educação integral dos alunos, que enxergue esses indivíduos em sua totalidade e que possibilite o acesso deles às atividades que despertem sua consciência de cultura, esporte, lazer, ciências e sociedade é um compromisso que deve ser assumido pelo Estado, a sociedade em geral e a comunidade escolar. 
Consideramos que a construção e o desenvolvimento de tal projeto educativo vão além do aumento da jornada escolar e do acesso às atividades caracterizadas como oficinas extracurriculares. Essa ação perpassa o envolvimento de todos os componentes curriculares e das atividades complementares e integradoras referentes a eles, bem como a maneira como tais atividades estão relacionadas ao conteúdo desenvolvido como um todo.

A Educação Física deve estar, como as demais disciplinas, comprometida em fazer com que cada momento na escola seja pedagógico e que todas as atividades oferecidas estejam articuladas, estabelecendo um projeto único de educação do sujeito em sua totalidade.

Ainda que tenhamos encontrado algumas dificuldades nesse processo de ampliação da jornada em concomitância com a implementação da educação integral, cada vez mais se desenvolvem projetos mais amplos e comprometidos da Educação Física com a educação escolar formal, os quais trazem consigo elementos para a formação de indivíduos sociais e políticos capazes de compreender a sociedade e transformá-la.

\section{Referências}

BRACHT, Valter. A constituição da teorias pedagógicas da Educação Física. Cadernos Cedes, Campinas, ano XIX, n. 48, 1999. Disponível em: <http://www.scielo.br/pdf/ccedes/v19n48/v1948a05.pdf>. Acesso em: 11 maio 2016

CAVALIERE, Ana Maria. Tempo de escola e qualidade na educação pública. Educação e Sociedade, Campinas, v. 28, n. 100, p. 1015-1035, 2007. Disponível em: <http://www.scielo.br/pdf/es/v28n100/a1828100>. Acesso em: 12 abr. 2016

. Escolas de tempo integral versus alunos em tempo integral. Em Aberto, Brasília, v. 22, n. 80, p. 51-63, 2009. Disponível em: <http://emaberto.inep.gov.br/index.php/emaberto/article/view/2220/2187>. Acesso em 12 abr. 2016

Escola pública de tempo integral no Brasil. Filantropia ou política de estado? Educação e Sociedade, Campinas, v. 35, n. 129, p. 1205-1222, 2014. Disponível em: <http://www.scielo.br/pdf/es/v35n129/0101-7330-es-35-129-01205.pdf>. Acesso em: 12 abr. 2016

CLANDININ, D. Jean. CONNELLY, F. Michael. Pesquisa narrativa. São Paulo: ABEU, 2011.

DUARTE, Newton. A individualidade para si. 3. ed. Campinas: Autores Associados, 2013.

FACCI, Marilda Gonçalves Dias. Valorização ou esvaziamento do trabalho do professor? Campinas: Autores Associados, 2004.

FRIGOTTO, Gaudêncio. O enfoque materialista histórico na pesquisa educacional. In: FAZENDA, Ivani. (Org.). Metodologia da Pesquisa Educacional. São Paulo: Cortez, 1987.

MARTINS, Ligia Márcia. As aparências enganam: divergências entre o materialismo histórico dialético e as abordagens qualitativas de pesquisa. In: TULESKI, Silvana Calvo; CHAVES, Marta; Leite, HILUSCA ALVES. (Org.) Materialismo histórico-dialético como fundamento da psicologia histórico-cultural. Maringá: EDUEM, 2015. 
MEDINA, João Paulo Subirá. A Educação Física Cuida do Corpo... e "mente". 24. ed. Campinas: Papirus, 2008.

MOLL, Jaqueline; LECLERC, Gesuína de Fátima Elias. Diversidade e tempo integral: a garantia dos direitos sociais. Revista Retratos da Escola, Brasília, v. 7, n. 13, p. 291-304, 2013. Disponível em: <http://retratosdaescola.emnuvens.com.br/rde/article/view/306/476>. Acesso em: 17 jul. 2017.

PIATTI, Célia Beatriz; URT, Sônia da Cunha. Memórias em Tessituras: registros de histórias, vida e trabalho. Revista Teias, Rio de Janeiro, v. 14, n. 37, p. 102-117, 2014. Disponível em: <http://www.e-publicacoes.uerj.br/index.php/revistateias/article/view/24423>. Acesso em: 11 jul. 2016

SAVIANI, Demerval. Marxismo, educação e pedagogia. In: SAVIANI, Dermeval. DUARTE, Newton. (Org.). Pedagogia histórico-crítica e luta de classes na educação escolar. Campinas: Autores Associados, 2015.

SILVA, Júnior Vagner Pereira da. Educação Física nos anos iniciais do ensino fundamental em Campo Grande/MS. Revista Brasileira de Ciência e Movimento, Brasília, v. 23, n. 2, p. 22-31, 2015. Disponível em: <https://portalrevistas.ucb.br/index.php /RBCM/article/ view/4607>. Acesso em: 17 jul. 2017.

SOARES, Carmen Lúcia et al. Metodologia do Ensino de Educação Física. São Paulo: Cortez, 1992.

URT, Sônia da Cunha; SIMÃO, Clarice. A Pesquisa em Educação e o Recurso Metodológico das Narrativas: uma aproximação com a Teoria Histórico-cultural. Revista Teias, Rio de Janeiro, v. 14, n. 31, p. 109-120, 2013. Disponível em: <http://www.epublicacoes.uerj.br/index.php/revistateias/article/view/24331>. Acesso em: 17 abr. 2016

VIGOTSKI, Liev Semionovich. Psicologia Pedagógica. Trad. Claudia Schilling. São Paulo: Artmed, 2003.

A Formação Social da Mente. Trad. José Cipolla Neto, Luis Silveira Menna Barreto e Solange Castro Afeche. 7. ed. São Paulo: Martins Fontes. 2007.

Recebido em: 02/12/2017

Revisado em: 09/08/2018

Aprovado em: 10/08/2018

Endereço para correspondência:

sol_balbinoms@hotmail.com

Solange Izabel Balbino

Universidade Federal de Mato Grosso do Sul, Centro de Ciências Humanas e Sociais da UFMS, Departamento de Ciências Humanas.

Cidade Universitária s/n - Caixa Postal 549

Cidade Universitária

79070900 - Campo Grande, MS - Brasil - Caixa-postal: 549 